Supporting Information for:

\title{
Camphorane as a renewable diesel blendstock produced by cyclodimerization of myrcene
}

Orion Staples, ${ }^{\dagger}$ Juan H. Leal, ${ }^{\ddagger}$ Patrick A. Cherry, ${ }^{\S}$ Charles S. McEnally,${ }^{\S}$ Lisa D. Pfefferle ${ }^{\S}$ Troy A.

\author{
Semelsberger, $₫$ Andrew D. Sutton,$^{\dagger}$ and Cameron M. Moore ${ }^{\dagger, *}$
}

${ }^{\dagger}$ Chemistry Division, MS K558, Los Alamos National Laboratory, Los Alamos, NM 87545.

¥Materials Physics Applications Division, MS K793, Los Alamos National Laboratory, Los Alamos, NM 87545.

\$Department of Chemical and Environmental Engineering, Yale University, New Haven, CT 06520.

*To whom correspondence should be addressed. E-mail: cameron_moore@lanl.gov

\section{Contents}

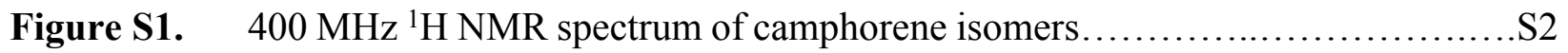

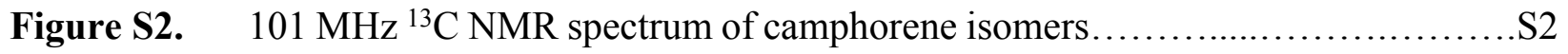

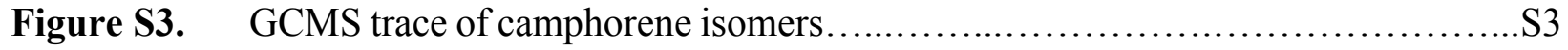

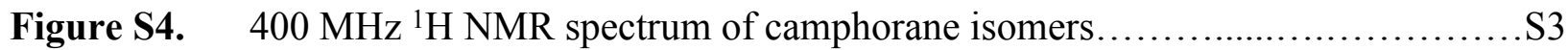

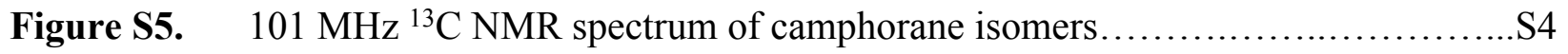

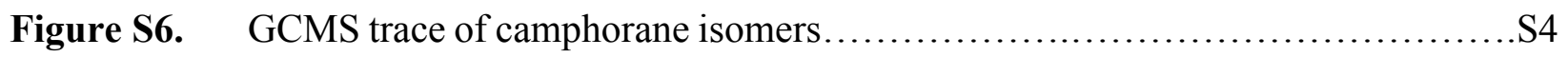

Table S1. Assignment of GCMS peaks in camphorane................................ 5

Figure S7. $\quad{ }^{1} \mathrm{H}$ NMR overlay spectra of camphorene and camphorane isomers...............S5

Figure S8. $\quad{ }^{13} \mathrm{C}$ NMR overlay spectra of camphorene and camphorane isomers..............S6

Figure S9. GCMS trace of commercial myrcene...................................... 6

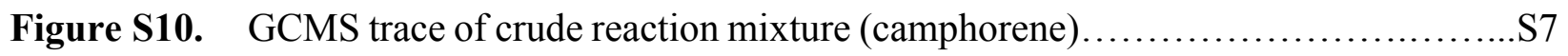

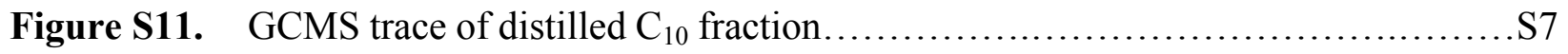

Figure S12. LSSR signal for camphorane as a function of the camphorane flowrate...........S8

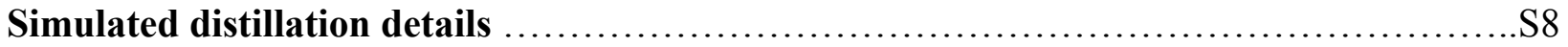

Figure S13. Normal boiling point of $\mathrm{C}_{8}-\mathrm{C}_{20} n$-alkanes as a function of $\mathrm{GC}$ retention time...S9

Figure S14. Kinematic viscosity of camphorane as a function of temperature...............S9

Figure S15. Kinematic viscosity of camphorane/diesel blends........................... 10

Figure S16. Density of camphorane/diesel blends at various temperatures................S10

Estimation of the Effect of Aromatic Impurities on the Measured YSI..................S11

Figure S17. Estimated YSIs for each camphorane and aromatic isomer..................S12

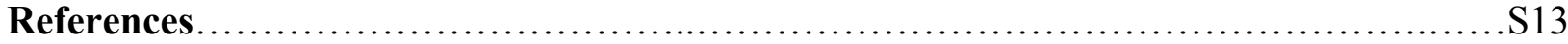




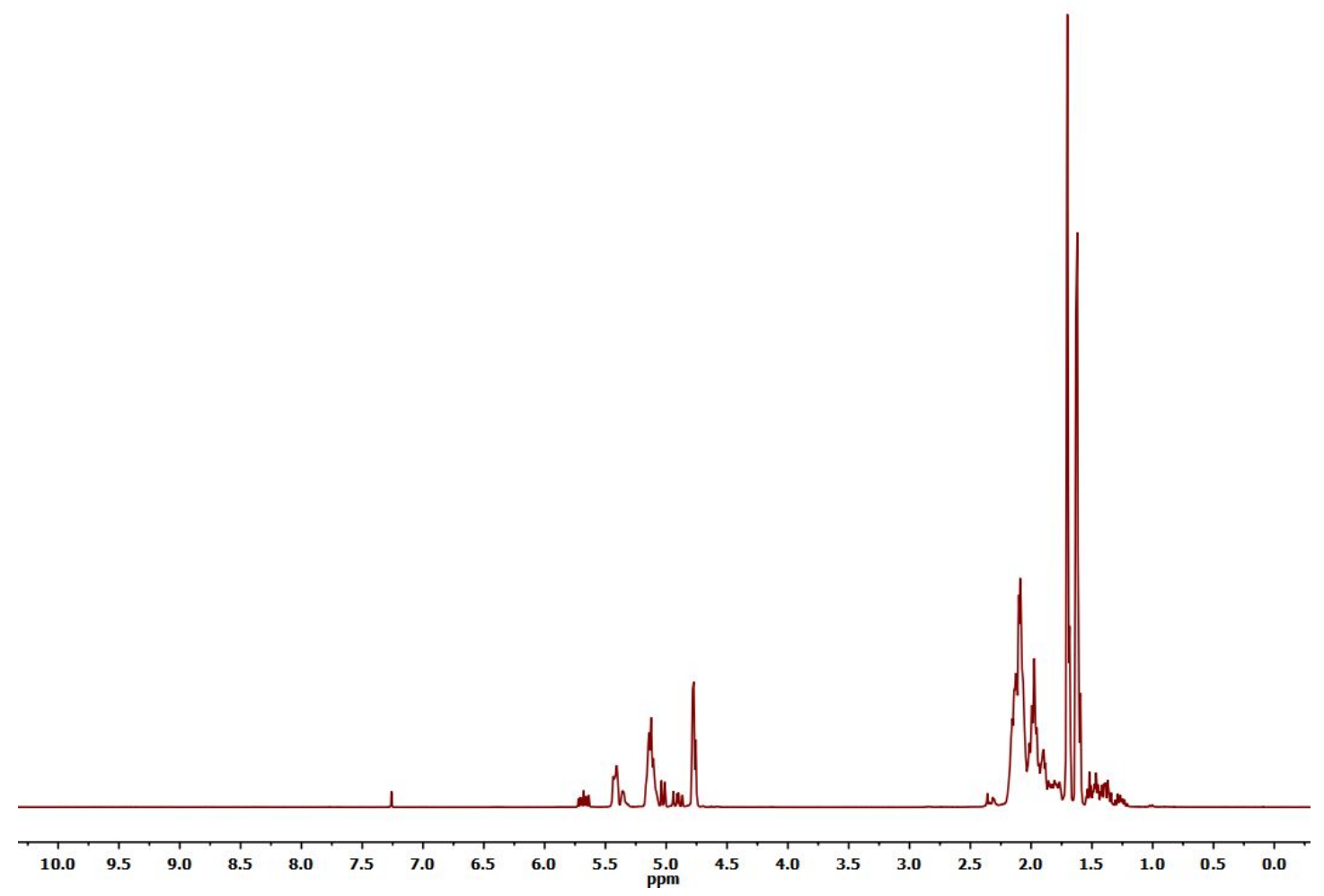

Figure S1. $400 \mathrm{MHz}{ }^{1} \mathrm{H}$ NMR spectrum of camphorene isomers.

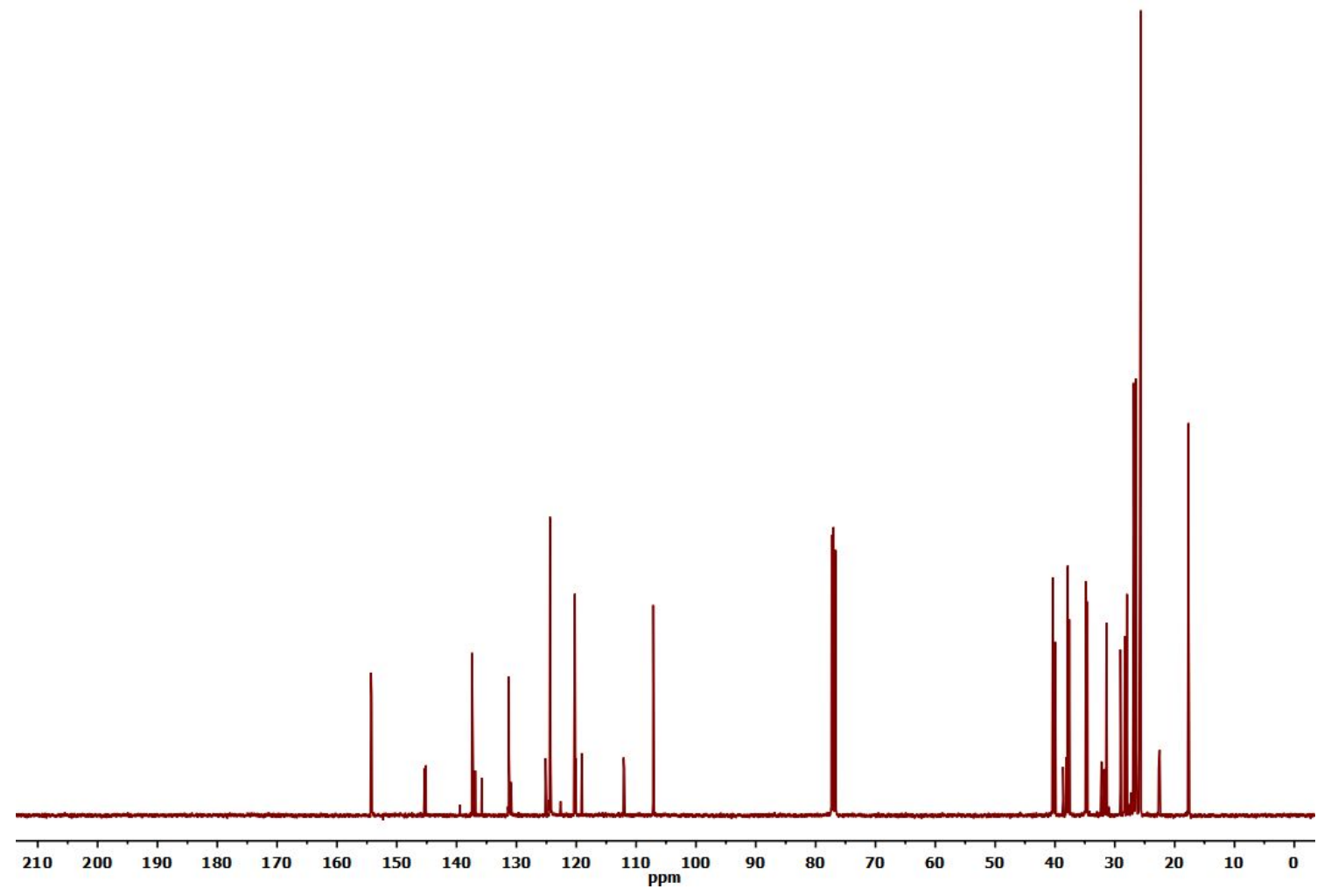

Figure S2. $101 \mathrm{MHz}{ }^{13} \mathrm{C}$ NMR spectrum of camphorene isomers. 


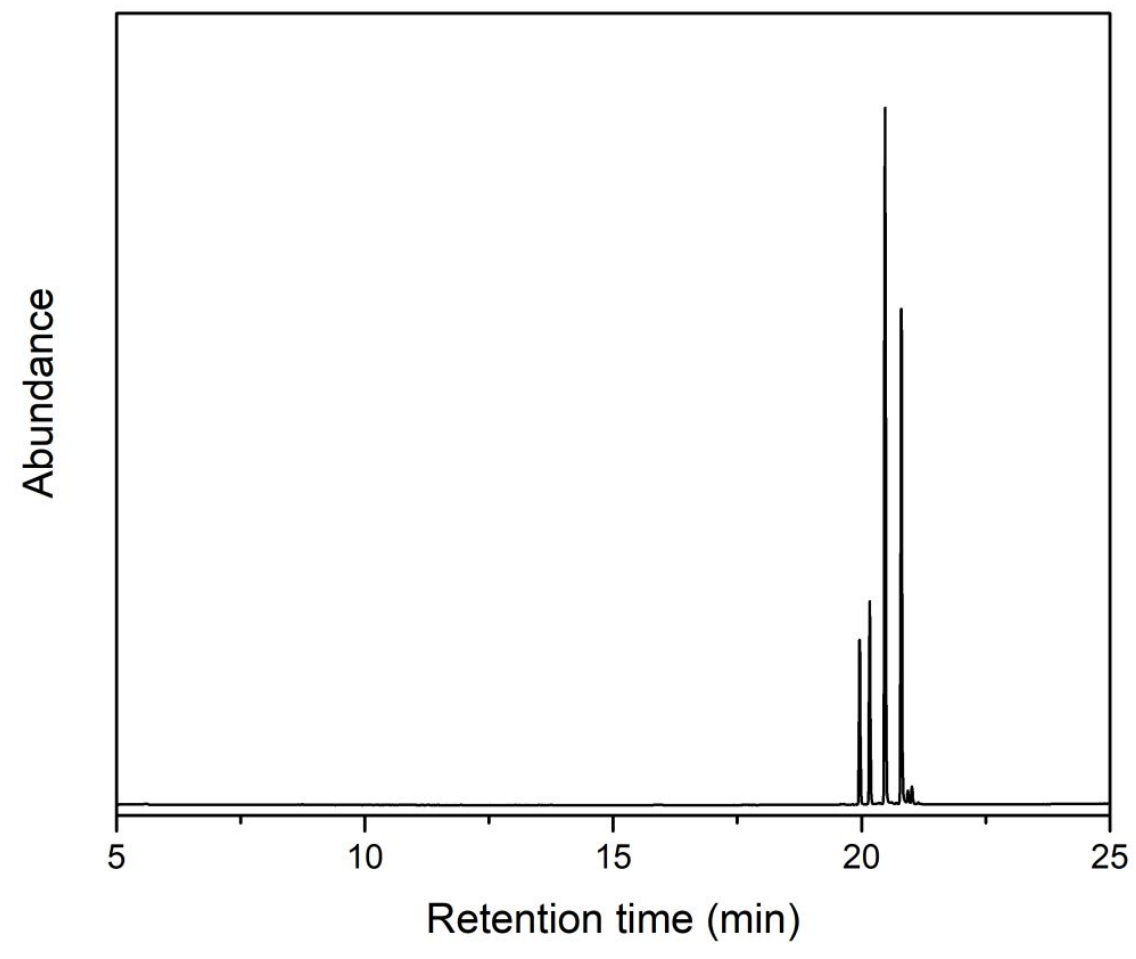

Figure S3. GCMS trace of camphorene isomers.

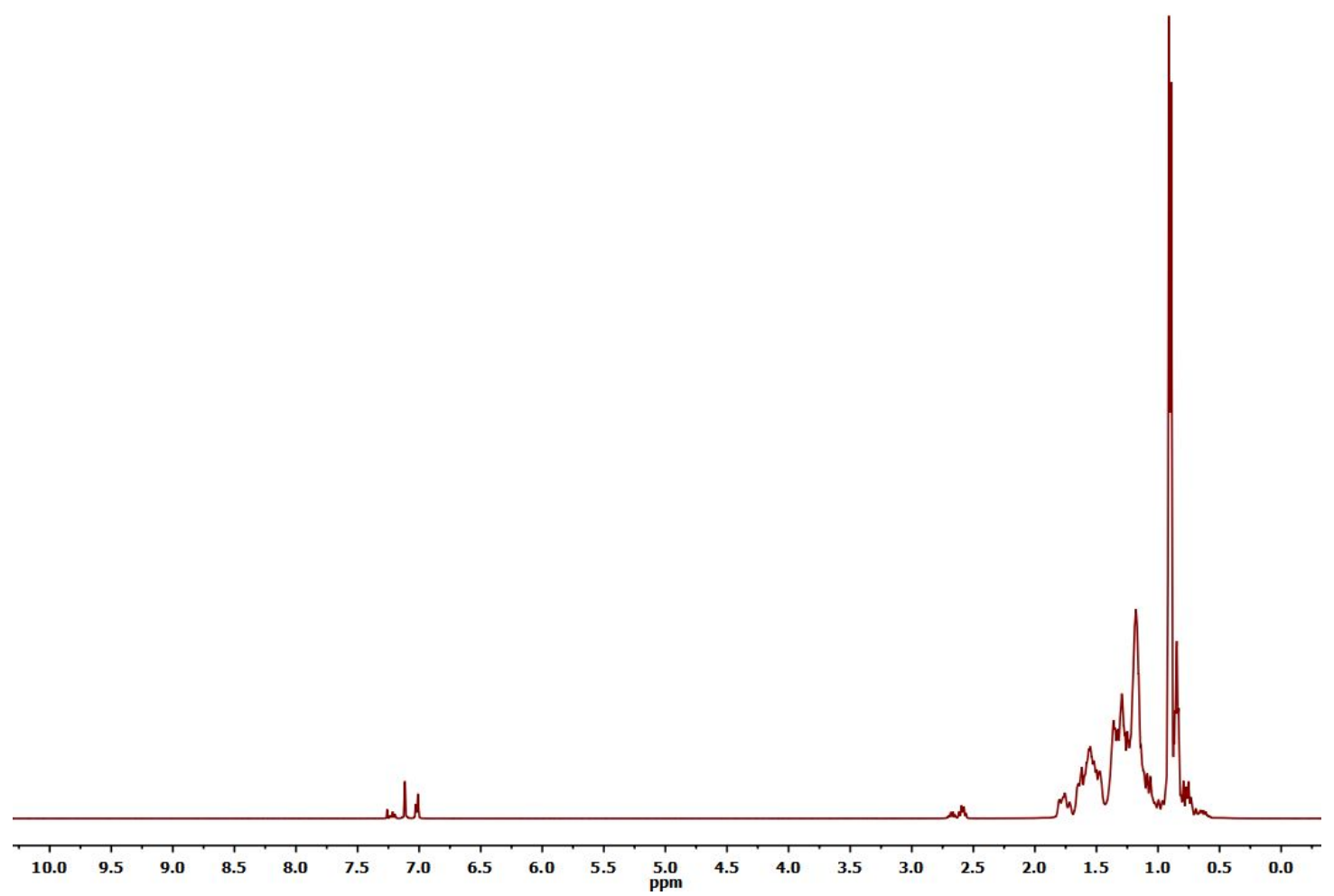

Figure S4. $400 \mathrm{MHz}{ }^{1} \mathrm{H}$ NMR spectrum of camphorane isomers. 


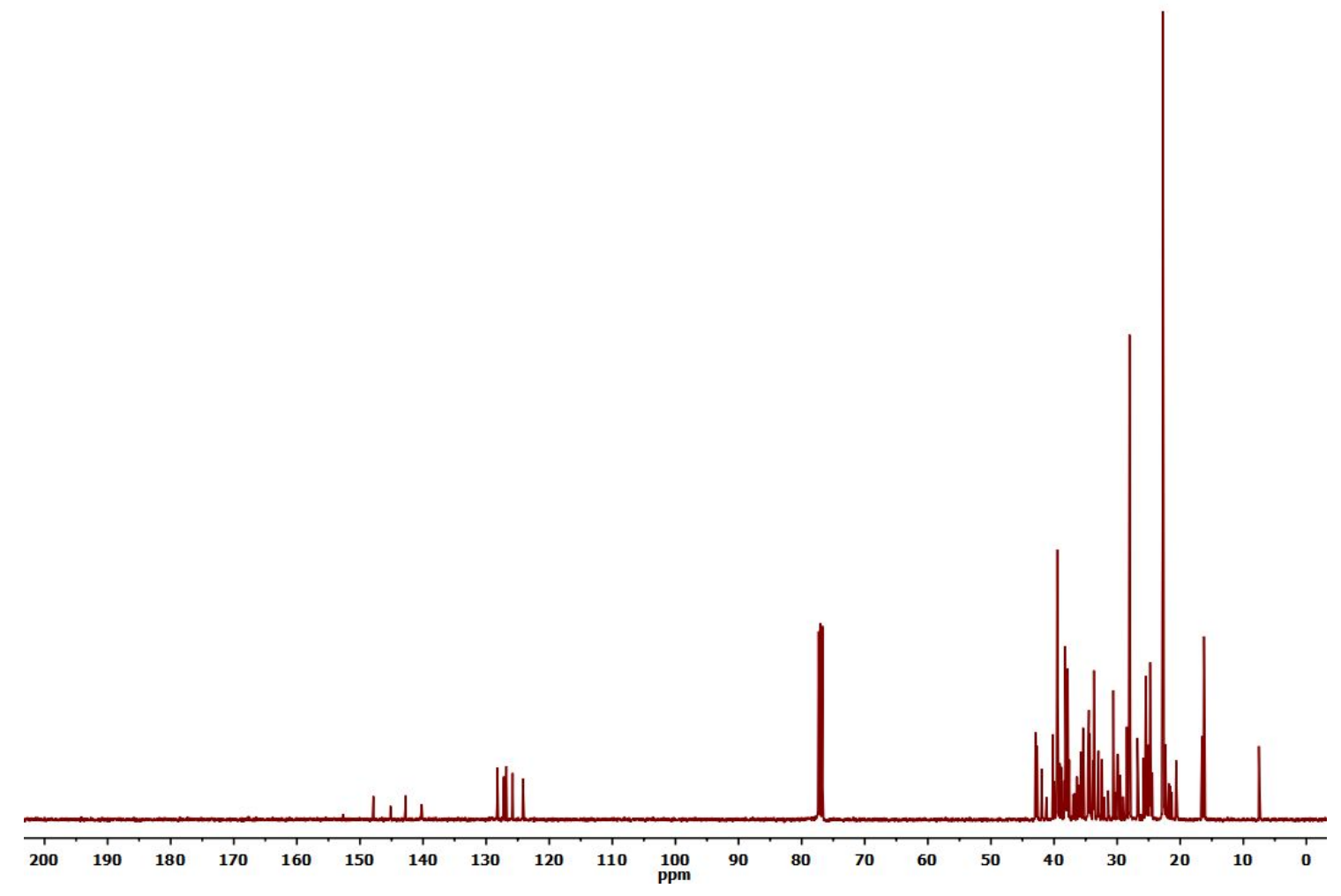

Figure S5. $101 \mathrm{MHz}{ }^{13} \mathrm{C}$ NMR spectrum of camphorane isomers.

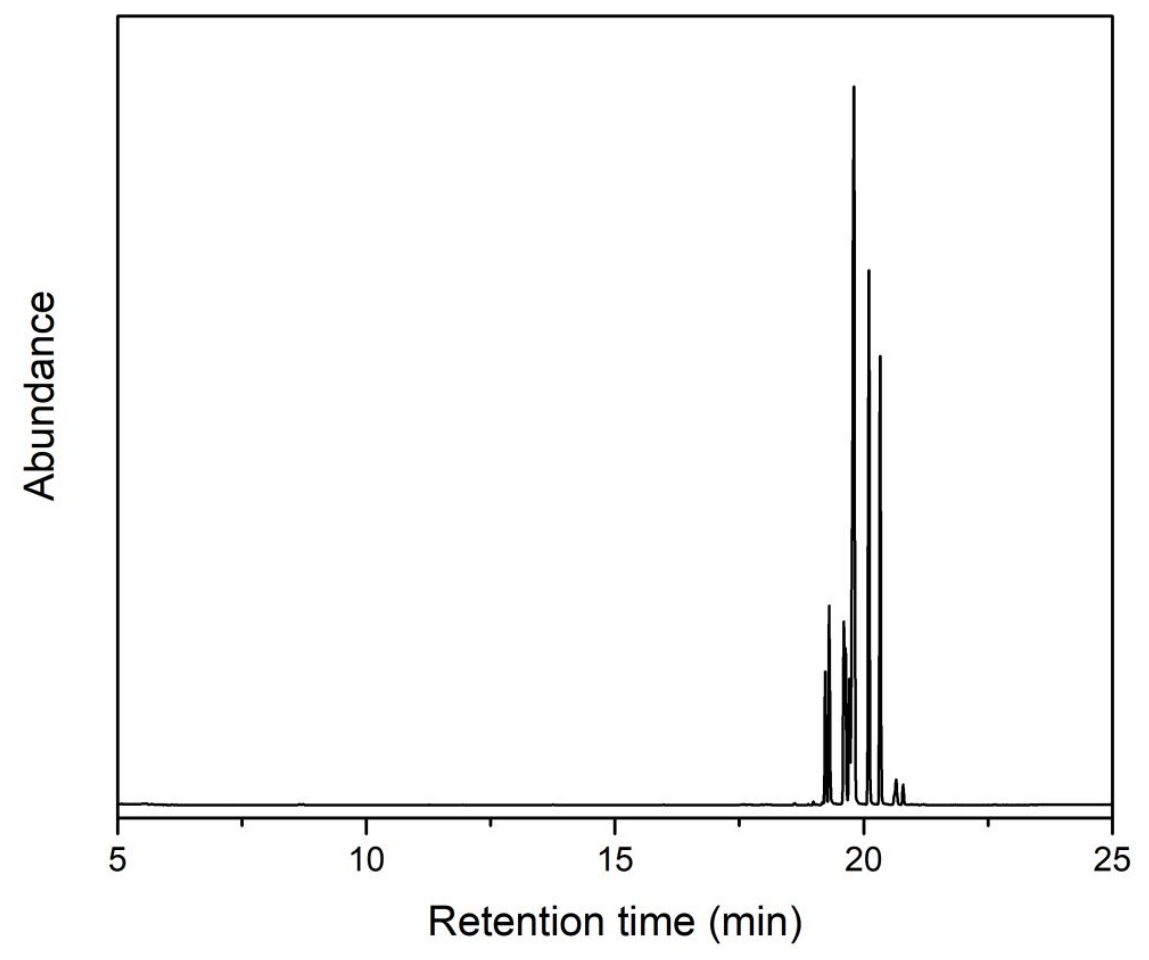

Figure S6. GCMS trace of camphorane isomers. 
Table S1. Assignment of GCMS peaks in camphorane and relative abundance, quantified using an FID detector.

\begin{tabular}{cccc}
\hline Retention time (min) & Parent ion (m/z) & Assignment & Relative abundance \\
\hline 19.23 & 251 & camphorane $-\mathrm{C}_{2} \mathrm{H}_{5}(\mathrm{Et} \cdot)$ & $4.4 \%$ \\
19.31 & 274 & aromatic & $6.7 \%$ \\
19.60 & 251 & camphorane $-\mathrm{C}_{2} \mathrm{H}_{5}(\mathrm{Et} \cdot)$ & $5.8 \%$ \\
19.64 & 280 & camphorane & $5.2 \%$ \\
19.71 & 274 & aromatic & $4.3 \%$ \\
19.81 & 280 & camphorane & $39.8 \%$ \\
20.11 & 280 & camphorane & $18.6 \%$ \\
20.33 & 280 & camphorane & $15.2 \%$ \\
\hline
\end{tabular}
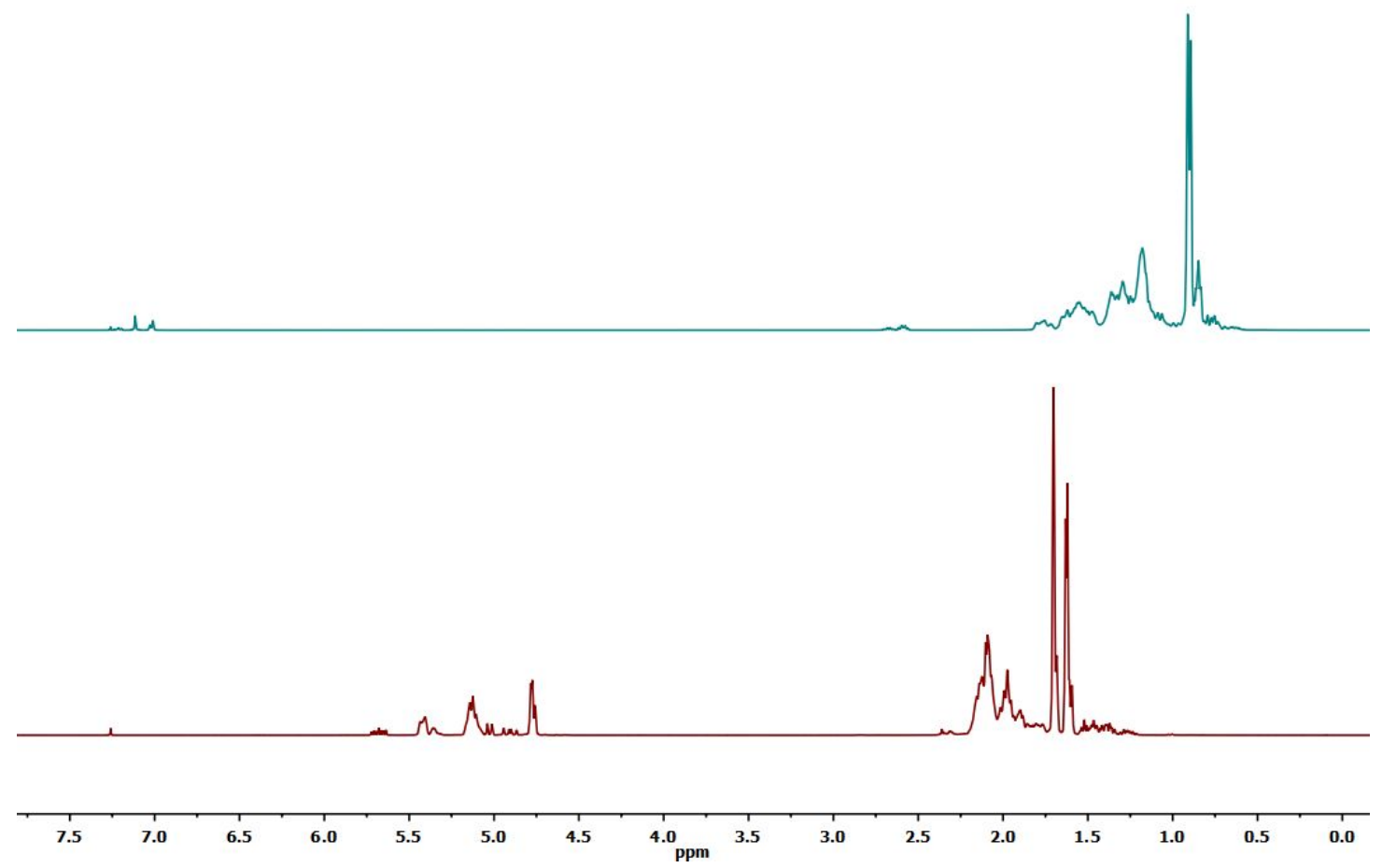

Figure S7. ${ }^{1} \mathrm{H}$ NMR overlay spectra of camphorene (bottom) and camphorane (top) isomers. 

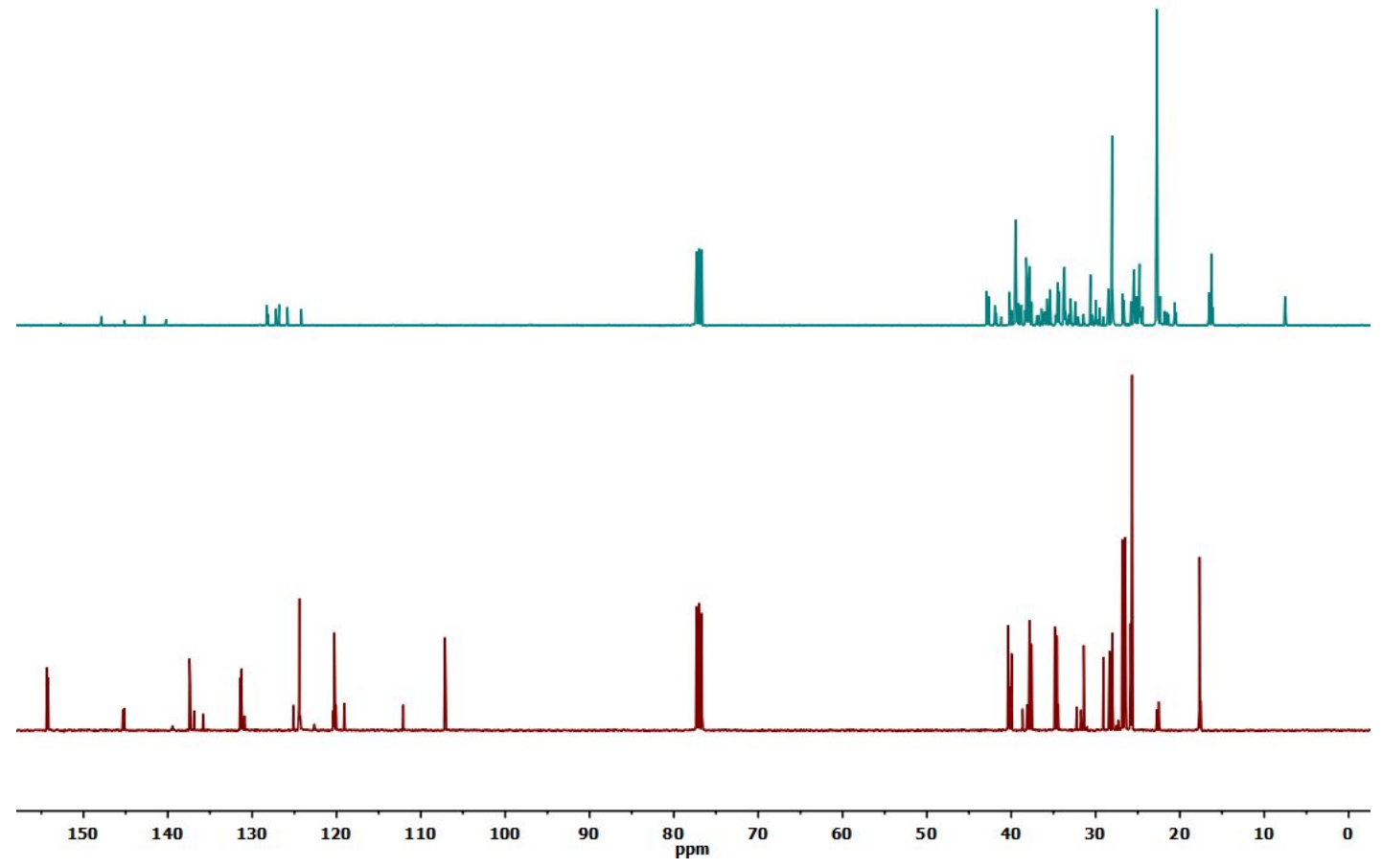

Figure S8. ${ }^{13} \mathrm{C}$ NMR overlay spectra of camphorene (bottom) and camphorane (top) isomers.

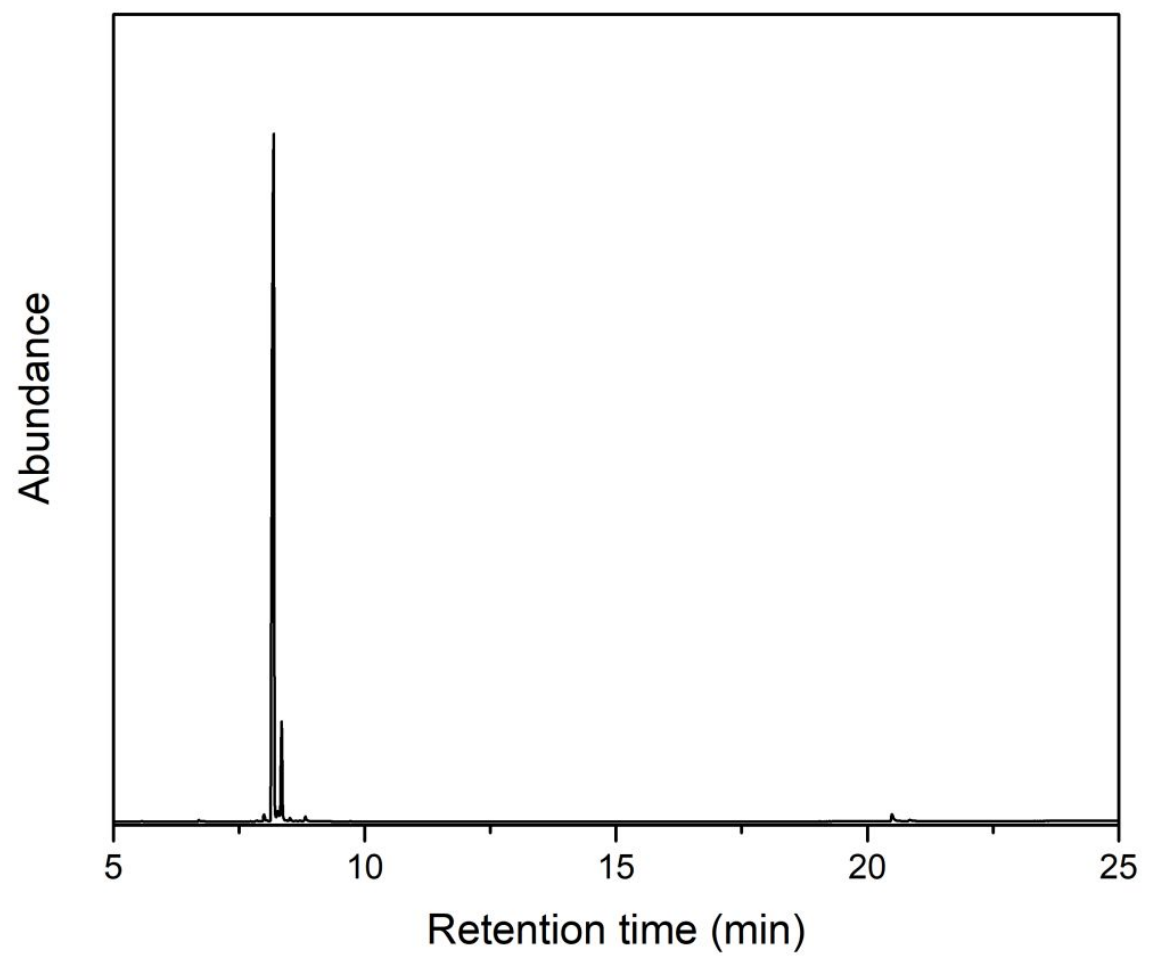

Figure S9. GCMS trace of commercial myrcene. 


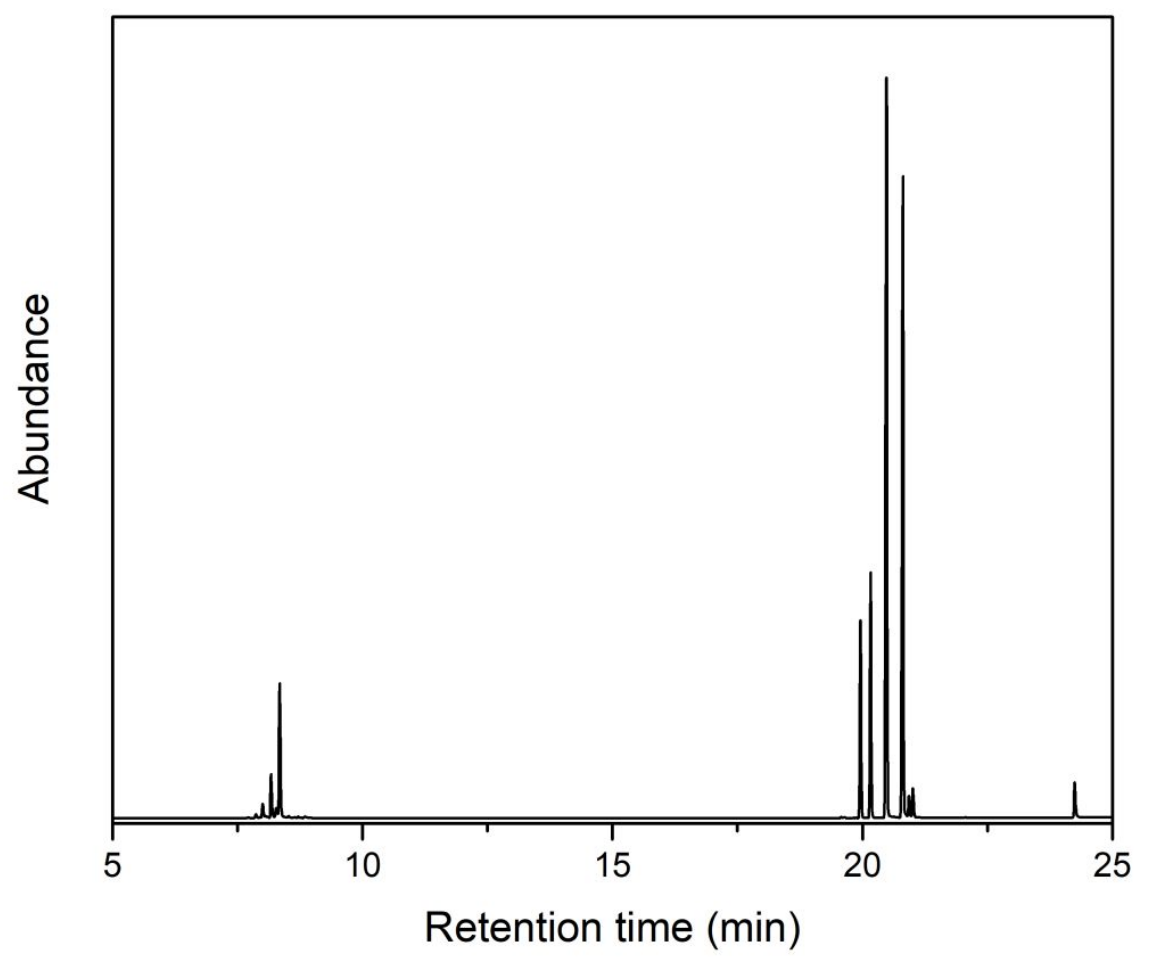

Figure S10. GCMS trace of crude reaction mixture (camphorene isomers).

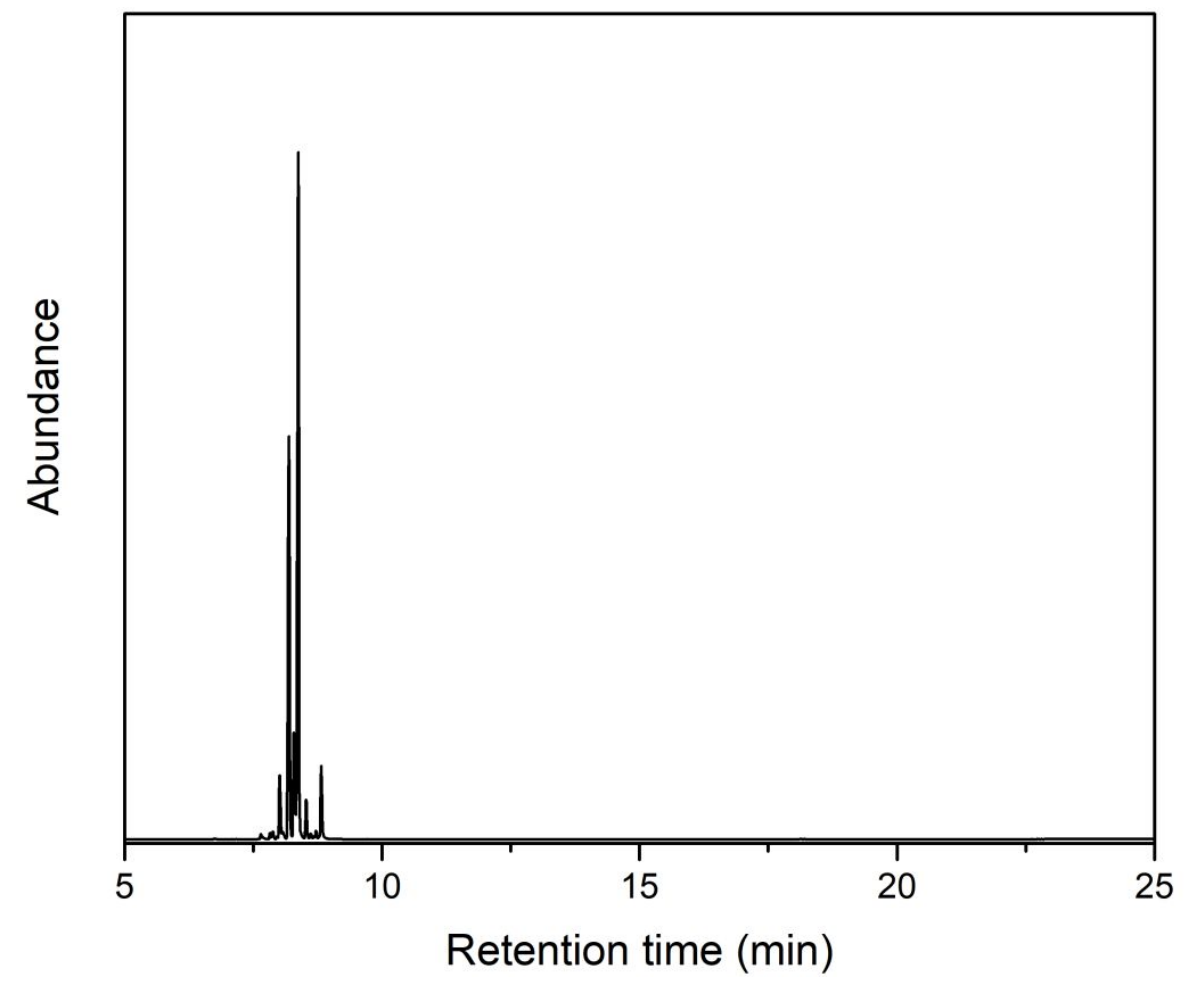

Figure S11. GCMS trace of distilled $\mathrm{C}_{10}$ fraction. 


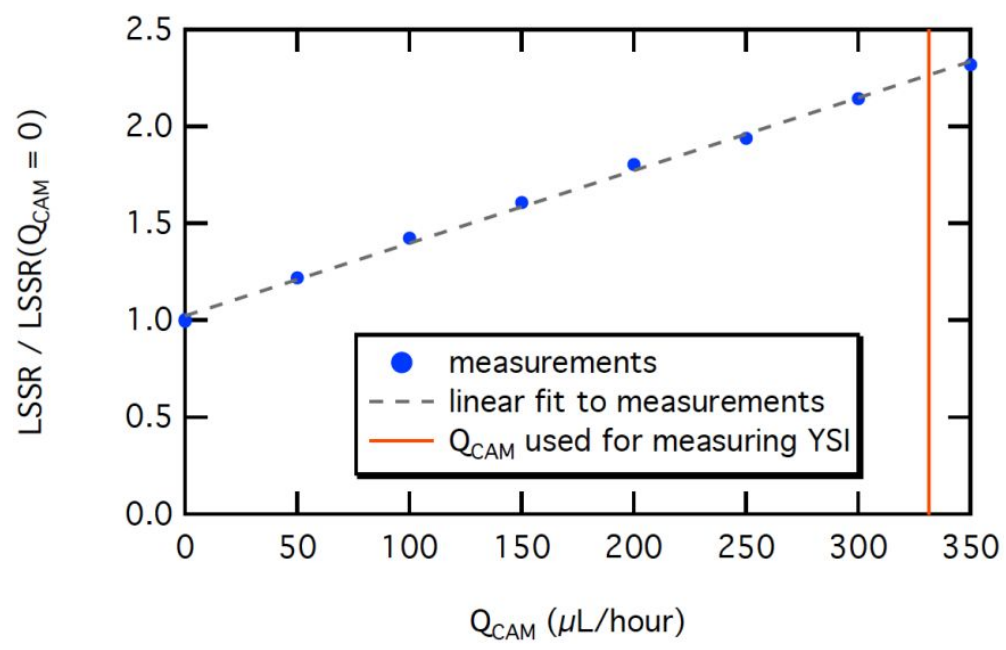

Figure S12. LSSR signal for camphorane-doped flames as a function of the liquid-phase camphorane flowrate $\left(\mathrm{Q}_{\mathrm{CAM}}\right)$ injected into the methane/nitrogen fuel mixture.

\section{Simulated distillation details}

Correlation of known boiling point to gas chromatograph (GC) retention time can be used to simulate distillation of fuel mixtures, as described in ASTM D2887. Here we used simulated distillation to determine the boiling point of camphorane. ${ }^{1}$ Samples were analyzed on an Agilent 7890 GC system equipped with an Agilent 5975 mass selective detector (MSD) and flame ionization detector (FID) and CP-Sil $5 \mathrm{CB}$ analytical column $(30 \mathrm{~m} \times 0.25 \mathrm{~mm} \times 0.25 \mathrm{~mm})$. The heating profile was as follows: $38{ }^{\circ} \mathrm{C}$ initial temperature $\left(3\right.$ minute hold time), $10{ }^{\circ} \mathrm{C} / \mathrm{min}$ ramp rate until $300^{\circ} \mathrm{C}$ (5 minute hold time). An analytical standard solution (Sigma Aldrich, product number 04070) of $n$-octane through eicosane in hexane $(\sim 40 \mathrm{mg} / \mathrm{L}$ each $)$ was injected and used to generate a correlation of boiling point to $\mathrm{GC}$ retention time (Figure S13). The boiling point range of camphorane was then determined by injection into the GC and determination of retention time for the first and last eluting components. 


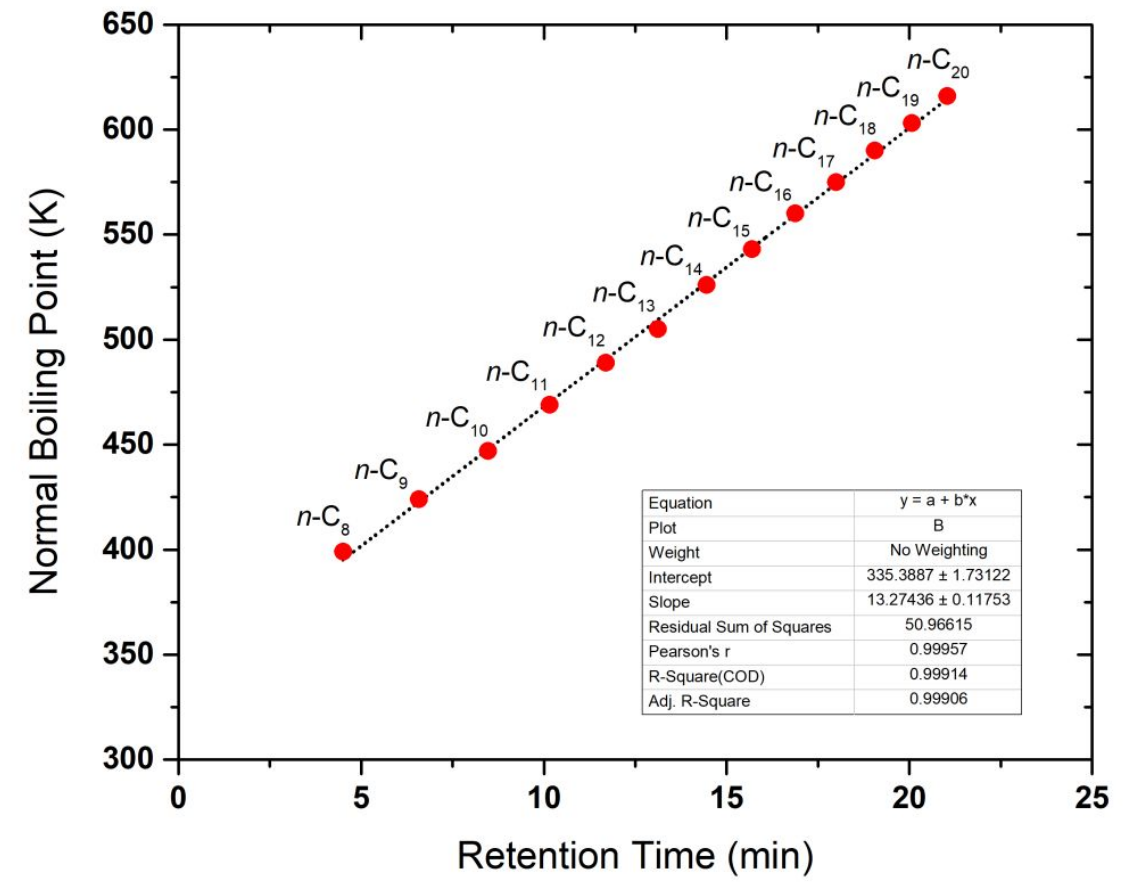

Figure S13. Normal boiling point of $\mathrm{C}_{8}-\mathrm{C}_{20} n$-alkanes as a function of $\mathrm{GC}$ retention time.

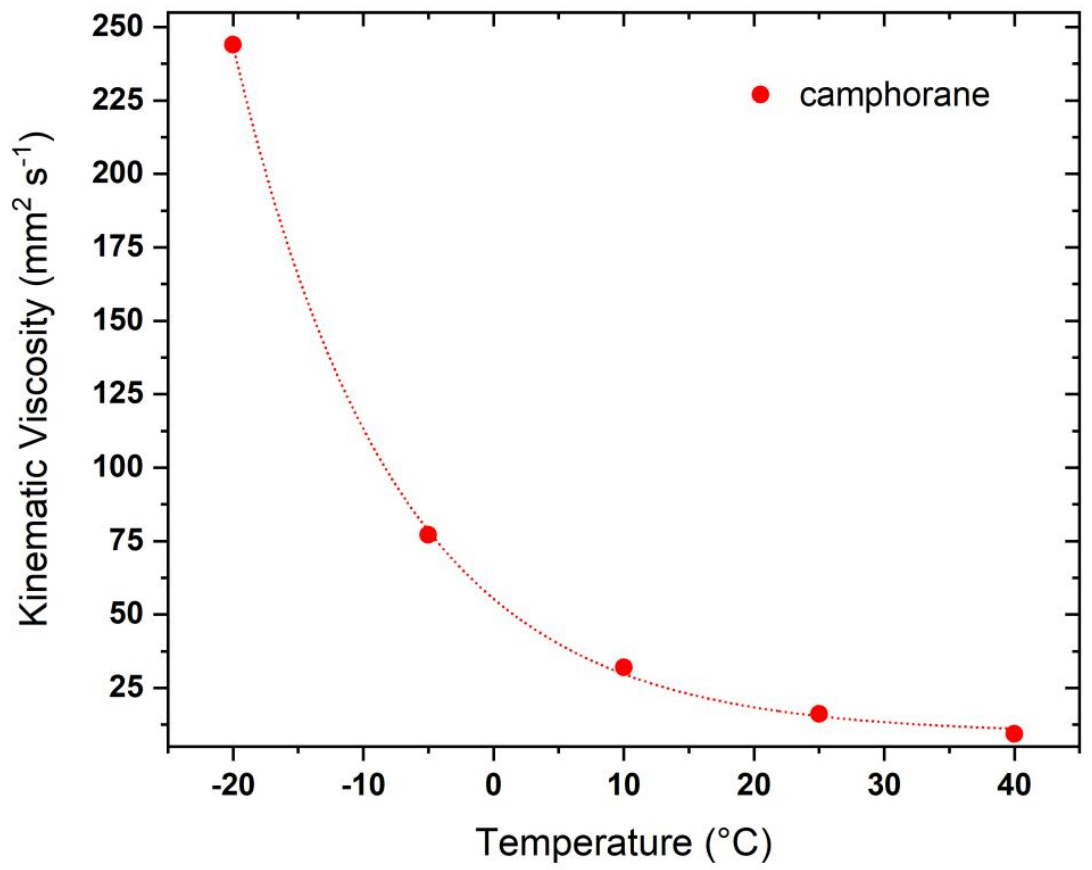

Figure S14. Kinematic viscosity of camphorane as a function of temperature. 


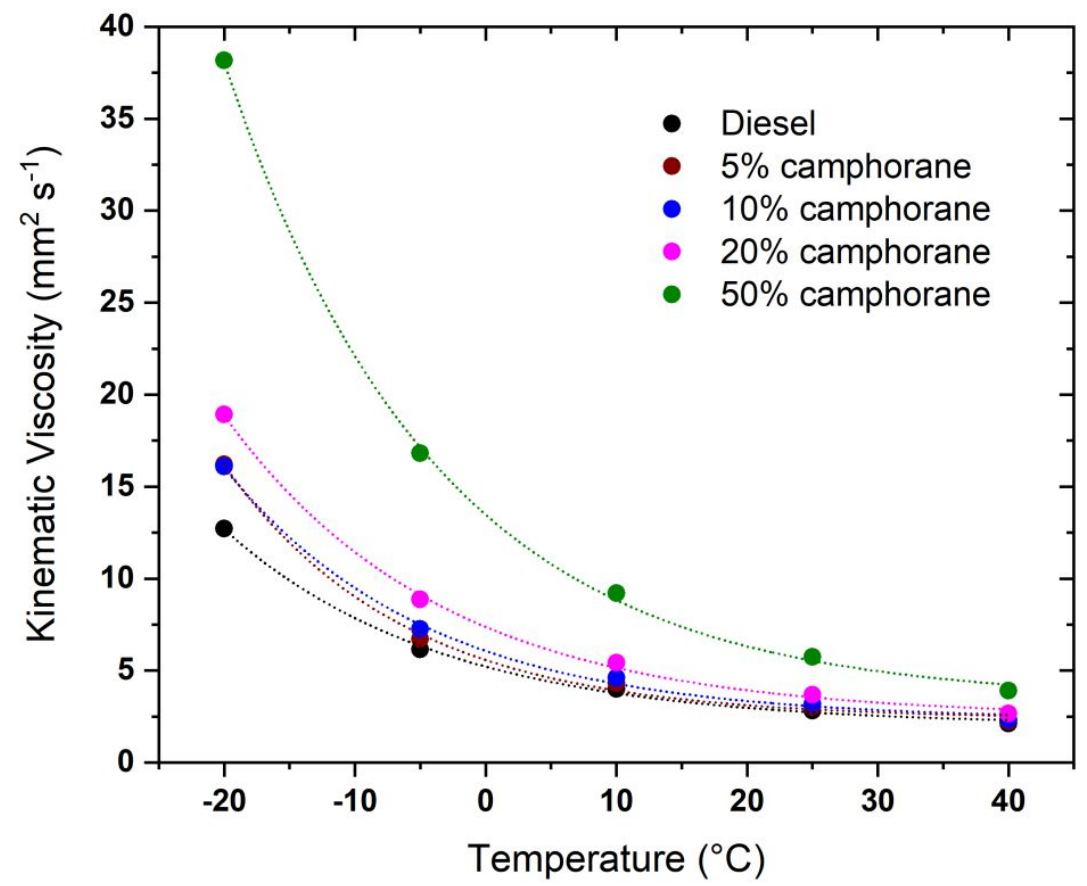

Figure S15. Kinematic viscosity of camphorane/diesel blends as a function of temperature.

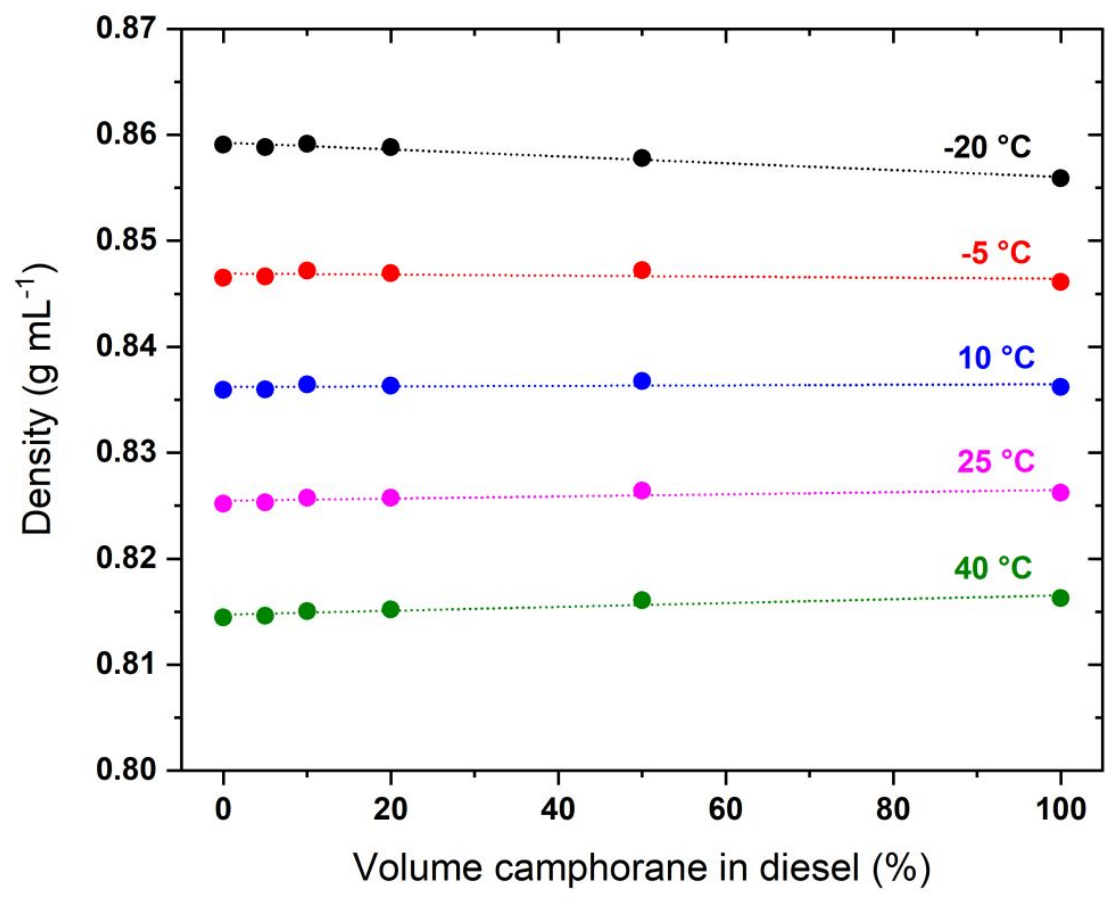

Figure S16. Density of camphorane/diesel blends at various temperatures. 


\section{Estimation of the Effect of Aromatic Impurities on the Measured YSI}

The YSIs of each camphorane and aromatic isomer shown in Figure 2 were estimated using a group contribution method $(\mathrm{GCM}){ }^{2}$ The results are shown in Figure S17. All six species are "inliers", meaning the GCM has adequate training data from earlier measurements of branched alkanes, alkyl-substituted cycloalkanes, and alkylbenzenes to estimate the contribution of each carbon-entered group in the new molecules. Meta- and para- isomers of cyclic compounds have the same carbon-centered groups, so camphoranes I and II, camphoranes III and IV, and aromatics I and II are degenerate within the GCM and have the same predicted YSI. The first and second set of camphoranes do differ in that the tertiary ring carbon and one tertiary side-chain carbon in $\mathbf{I} / \mathbf{I I}$ are replaced by a quaternary ring carbon and secondary side-chain carbon in III/IV; however, this makes little difference and the predicted YSIs for the two sets are identical to within the model uncertainty. The YSIs of the aromatics are dramatically larger than those of the camphoranes, by about $240 \%$. This difference occurs because the benzenoid ring is very stable in pyrolysis conditions; thus, while the camphoranes decompose to alkenes and must synthesize aromatics from scratch, the aromatics decompose to benzylic species that serve as nuclei for multi-ring aromatics. Overall, the estimated values are $\mathrm{YSI}_{\text {est,camphoranes }}=161$ and $\mathrm{YSI}_{\text {est,aromatics }}=383$.

To estimate the impact of the aromatic impurities on the measured YSIs, we assumed that the GCM prediction of the ratio between the camphorane and aromatic YSIs is accurate, and that the blending behavior for YSI is linear; i.e.,

$$
\mathrm{YSI}_{\mathrm{mix}}=\sum_{i} X_{i} * \mathrm{YSI}_{i}
$$

where $\mathrm{YSI}_{\text {mix }}$ is the YSI of the mixture, the sum is over all of the components $i$ of the mixture, $X_{i}$ is the mole fraction of component $i$, and $\mathrm{YSI}_{i}$ is the YSI of component $i$ as a pure compound. his linear blending assumption is justified by the results in Figure 6. With the predicted value $\mathrm{YSI}_{\text {aromatics }} / \mathrm{YSI}_{\text {camphoranes }}=2.4$, and the measured values $\mathrm{YSI}_{\text {mix }}=215, X_{\text {camphorenes }}=0.89$, and $X_{\text {aromatics }}=0.11$, we conclude $\mathrm{YSI}_{\text {camphoranes }}=187$ and $\mathrm{YSI}_{\text {aromatics }}=445$. These values are in reasonable agreement with the GCM, which tends to underpredict the YSIs of species with very large carbon numbers. 
<smiles>CC(C)CCCC1CCC(C(C)CCCC(C)C)CC1</smiles><smiles>CC(C)CCCC1CCCC(C(C)CCCC(C)C)C1</smiles><smiles>CCC1(CCCC(C)C)CCC(CCCC(C)C)CC1</smiles><smiles>CCC1(CCCC(C)C)CCCC(CCCC(C)C)C1</smiles><smiles>CC(C)CCCc1ccc(C(C)CCCC(C)C)cc1</smiles><smiles>CC(C)CCCc1cccc(C(C)CCCC(C)C)c1</smiles>

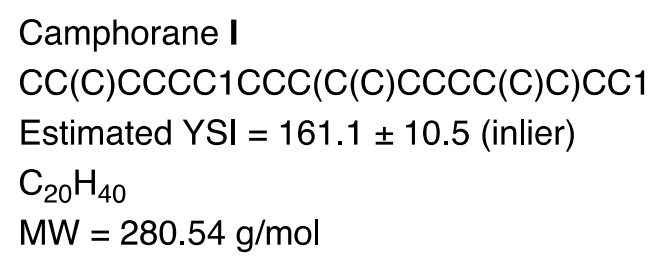

Camphorane II $\mathrm{CC}(\mathrm{C}) \operatorname{CcCC} 1 \mathrm{CC}(\mathrm{C}(\operatorname{CcCC}(\mathrm{C}) \mathrm{C}) \mathrm{C}) \mathrm{CCC} 1$ Estimated $\mathrm{YSI}=161.1 \pm 10.5$ (inlier)

$\mathrm{C}_{20} \mathrm{H}_{40}$

$\mathrm{MW}=280.54 \mathrm{~g} / \mathrm{mol}$

\section{Camphorane III}

$\mathrm{CC}(\mathrm{C}) \mathrm{CCCC} 1 \mathrm{CCC}(\mathrm{CCCC}(\mathrm{C}) \mathrm{C})(\mathrm{CC}) \mathrm{CC} 1$

Estimated $\mathrm{YSI}=160.4 \pm 15.6$ (inlier)

$\mathrm{C}_{20} \mathrm{H}_{40}$

$\mathrm{MW}=280.54 \mathrm{~g} / \mathrm{mol}$

Camphorane IV

$\operatorname{CCC} 1(\operatorname{CcCC}(\mathrm{C}) \mathrm{C}) \mathrm{CCCC}(\mathrm{CCCC}(\mathrm{C}) \mathrm{C}) \mathrm{C} 1$

Estimated $\mathrm{YSI}=160.4 \pm 15.6$ (inlier)

$\mathrm{C}_{20} \mathrm{H}_{40}$

$\mathrm{MW}=280.54 \mathrm{~g} / \mathrm{mol}$

Aromatic I

$\mathrm{CC}(\mathrm{CCCC}(\mathrm{C}) \mathrm{C}) \mathrm{C} 1=\mathrm{CC}=\mathrm{C}(\mathrm{CCCC}(\mathrm{C}) \mathrm{C}) \mathrm{C}=\mathrm{C} 1$

Estimated $\mathrm{YSI}=383.3 \pm 15.2$ (inlier)

$\mathrm{C}_{20} \mathrm{H}_{34}$

$\mathrm{MW}=274.48 \mathrm{~g} / \mathrm{mol}$

\footnotetext{
Aromatic II $\mathrm{CC}(\mathrm{CCCC}(\mathrm{C}) \mathrm{C}) \mathrm{C} 1=\mathrm{CC}=\mathrm{CC}(\mathrm{CCCC}(\mathrm{C}) \mathrm{C})=\mathrm{C} 1$

Estimated $\mathrm{YSI}=383.3 \pm 15.2$ (inlier)

$\mathrm{C}_{20} \mathrm{H}_{34}$

$\mathrm{MW}=274.48 \mathrm{~g} / \mathrm{mol}$
}

Figure S17. Estimated YSIs for each camphorane and aromatic isomer. 


\section{References}

1. Balakrishnan, M.; Sacia, E. R.; Sreekumar, S.; Gunbas, G.; Gokhale, A. A.; Scown, C. D.; Toste, F. D.; Bell, A. T. Novel pathways for fuels and lubricants from biomass optimized using life-cycle greenhouse gas assessment. Proc. Nat. Acad. Sci. 2015, 201508274.

2. Das, D. D.; St. John, P. C.; McEnally, C. S.; Kim, S.; Pfefferle, L. D. Measuring and predicting sooting tendencies of oxygenates, alkanes, alkenes, cycloalkanes, and aromatics on a unified scale. Combust. Flame 2018, 190, 349-364. 